УДК 665.7.032.53:676.085.2

\title{
МЕХАНОХИМИЧЕСКИЕ ПРЕВРАЩЕНИЯ КИСЛОРОДСОДЕРЖАЩИХ СОЕДИНЕНИЙ ЛИПИДОВ ТОРФА
}

\author{
() А.В. Савельева, Н.В. Юдина" \\ Институт химии нефтти Сибирского отделения Российской академии наук, \\ пр. Академический, 4, Томск, 634021 (Россия), e-mail: natal@ipc.tsc.ru
}

\begin{abstract}
Показано влияние механоактивации торфа на изменение выхода липидов и компонентного состава смолистой фракции. Механохимические превращения карбоновых кислот в кислых фракциях липидов сопровождаются незначительным снижением их количества и увеличением доли соединений с меньшей молекулярной массой. Отмечено, что после механоактивации торфа существенно снижается содержание насыщенных одноатомных спиртов.

Ключевые слова: механоактивация, липиды торфа, жирные кислоты, спирты, кетоны.
\end{abstract}

Работа выполнена при финансовой поддержке некоммерческой благотворительной организации «Благотворительный фонд В. Потанина», грант ГТ-02/11.

\section{Введение}

Липиды представляют собой большую группу природных гидрофобных соединений с разнообразной структурой и широким спектром биологической и антиоксидантной активности [1-4].

Структурное многообразие липидов в основном обусловлено наличием в их составе различных жирных кислот, отличающихся по длине, степени и характеру разветвления углеродной цепи, числу и положению двойных связей, природе и количеству других функциональных групп. Жирные кислоты входят в состав липидов высших растений, имеющих, как правило, четное число атомов углерода, и наследуемых липидами торфов [5-7].

Для достижения полноты выделения липидов из растительного сырья применяют многократную обработку растворителями различной полярности. Недостатками традиционной экстракционной технологии являются: использование токсичных и пожароопасных органических растворителей, низкая степень извлечения, многократное повторение экстрагирования и, как следствие, повышение производственных затрат и загрязнение окружающей среды. Механохимические методы получения биологически активных веществ растительного происхождения основаны на твердофазном превращении этих веществ в растворимые формы путем механической обработки растительного сырья и специально подобранных реагентов [8-10].

Использование предварительной механической активации позволяет достигать максимальной эффективности на стадии последующего экстрагирования. Ударно-сдвиговое воздействие сопровождается измельчением и разупорядочением структуры обрабатываемого материала. Последнее обстоятельство значительно облегчает выделение липидных компонентов.

Савельева Анна Викторовна - научный сотрудник, кандидат биологических наук, тел.: (3822) 49-27-56, e-mail: anna@ipc.tsc.ru

Юдина Наталья Васильевна - старший научный сотрудник, кандидат технических наук, тел.: (3822) 49-27-56, e-mail: natal@ ipc.tsc.ru
Значительная часть работ в этой области посвящена механохимическим превращениям битумных компонентов угля. Механическое воздействие на угли вызывает увеличение выхода битумов, в которых были идентифицированы $н$-алканы с меньшей молекулярной массой [11].

\footnotetext{
* Автор, с которым следует вести переписку.
} 
Действие знакопеременных динамических нагрузок на образцы сапропелевых и гумусовых углей в водной среде привело к изменению компонентного состава хлороформных битумов. В них уменьшалось содержание асфальтово-смолистых компонентов, при этом увеличился выход соединений с меньшей молекулярной массой - бензольных смол и масел. В спиртобензольных битумах наблюдалось снижение количества карбоксильных, кетонных, сложноэфирных групп и метиленовых структур [12, 13].

Механодеструкция твердых горючих ископаемых приводит к изменению содержания и состава высших жирных кислот в липидных экстрактах [14]. Их состав в большей степени изменяется при вибропомоле. Установлено, что механизм окисления при механохимической активации включает образование промежуточных продуктов, которые содержат остатки жирных кислот с разной длиной углеродной цепи.

Изучение изменений в составе и свойствах липидов при механохимической обработке представляет интерес с точки зрения их использования как источника биологически активных веществ и создания препаратов физиологического действия.

Цель работы - исследование состава кислородсодержащих соединений липидов торфов и их механохимических превращений.

\section{Экспериментальная часть}

В качестве объектов исследования использовали верховой сфагновый торф (степень разложения 5\% мас., зольность 3,7\% мас.).

Механоактивацию (МА) торфа проводили в планетарной мельнице АПФ-4 с дискретным режимом работы [9]. Ускорение воздействующих стальных шаров диаметром 10 мм составляло 200 м/с², время обработки - 2 и 5 мин.

Липиды из верхового сфагнового торфа экстрагировали смесью растворителей: спирт - хлороформ в соотношении $1: 1$ [15]. Растворители из липидного экстракта удаляли под вакуумом на роторном испарителе.

В липидах определяли перекисное (ГОСТ 26593-85), кислотное (ГОСТ 5985-79) и йодное (ГОСТ 5475-69) число.

Из липидного экстракта выделяли восковую и смолистую фракции. Экстракт $(6,5$ г) растворили в 100 мл 0,5 н. спиртового раствора гидроксида калия и нагревали в колбе с обратным холодильником на водяной бане в течение 1 ч. По окончании нагревания реакционную смесь разбавили водой в четыре раза. Полученную смесь экстрагировали диэтиловым эфиром трижды в делительной воронке. Эфирную фракцию объединяли и сушили на $\mathrm{Na}_{2} \mathrm{SO}_{4}$. Эфир отгоняли, остаток сушили до постоянного веса. Водную фракцию нейтрализовали разбавленной соляной кислотой до слабокислой среды (pH 4), полученную смесь экстрагировали эфиром дважды, экстракт объединяли, сушили над $\mathrm{Na}_{2} \mathrm{SO}_{4}$, эфир отгоняли, остаток сушили до постоянного веса [16].

Анализ соединений, экстрагированных гексаном, проводили на хромато-масс-спектрометрической квадрупольной системе GSMS-QP5050 Shimadzy, по методу MIM (multiple ion monitoring), сканируя массхроматограммы по характеристичным ионам в режиме программирования температуры: начальная температура $80{ }^{\circ} \mathrm{C}$, конечная - $290^{\circ} \mathrm{C}$, скорость - 2 град/мин, на капиллярной кварцевой колонке DB5-MS длиной 30 м × 0,32 мм [17].

\section{Обсуждение результатов}

К основным факторам, определяющим кинетические параметры экстракции липидов, относится надмолекулярное строение компонентов торфа. В соответствии с моделью частицы торфа [18], представляющей пространственную сетку сшитых макромолекул гуминовых кислот, гемицеллюлозы, целлюлозы, лигнина и липидов, для повышения доступности отдельных компонентов в процессе экстракции требуется применение механического воздействия. В результате механодеструкции торфа выход липидов увеличивается в 1,5 раза (табл. 1) [19].

Липиды торфа содержат сложную смесь органических соединений, которые можно объединить в две группы в зависимости от применяемого растворителя - воска и смолы. В таблице 1 показано изменение содержания в липидах воска и смолы в зависимости от времени МА торфа. После МА торфа в течение 2 мин в липидах значительно возрастает количество воска. 
Таблица 1. Влияние механоактивации торфа на выход и состав липидов

\begin{tabular}{c|c|c|c}
\hline \multirow{2}{*}{ Время м/а, } & \multicolumn{3}{|c}{ Содержание, \% мас. } \\
\cline { 2 - 4 } мин & липиды & воск & смола \\
\hline Без обработки & 4,6 & 36,0 & 64,0 \\
2 & 7,5 & 46,0 & 54,0 \\
5 & 6,2 & 42,0 & 58,0 \\
\hline
\end{tabular}

Сведения об элементном составе и атомные отношения Н/C и О/С позволяют оценить такие параметры структуры, как содержание ненасыщенных и кислородсодержащих фрагментов (табл. 2). Снижение атомного отношения Н/C, наблюдаемое для липидов торфа, обработанного в течение 2 мин, свидетельствует о повышении количества ненасыщенных соединений. Увеличение времени МА торфа приводит к насыщению непредельных связей за счет реакций окисления. Этот факт подтверждается значительным увеличением показателя О/С для липидов, выделенных из торфа после МА в течение 5 мин.

Значение отношений $\mathrm{H} / \mathrm{C}$ и О/С коррелирует с величиной кислотного, перекисного и йодного чисел (табл. 3). Кислотное число липидов после МА торфа возрастает, что согласуется с увеличением отношения О/С. Снижение значения перекисного числа свидетельствует о более высокой стабильности механоактивированных липидов при перекисном окислении. Повышение йодного числа липидов после МА связано, очевидно, с увеличением содержания ненасыщенных связей.

Методом хромато-масс-спектрометрии в липидах кислой фракции идентифицированы кислоты, спирты, кетоны, альдегиды, эфиры (табл. 4). В кислой фракции липидов из необработанного торфа в наибольшем количестве присутствуют кислоты и спирты, альдегиды и кетоны представлены практически в равных долях. После МА торфа снижается содержание кислот, спиртов и альдегидов.

Детальное исследование индивидуального состава указанных групп соединений показало, что жирные насыщенные кислоты из необработанного торфа представлены гомологическим рядом от $\mathrm{C}_{5} \mathrm{H}_{11} \mathrm{COOH}$ до $\mathrm{C}_{15} \mathrm{H}_{31} \mathrm{COOH}$ с преобладанием соединений с четным числом атомов углерода. Наиболее высоким содержанием характеризуется пальмитиновая кислота $\left(\mathrm{C}_{15} \mathrm{H}_{31} \mathrm{COOH}\right)$. После механообработки торфа повышается содержание кислот с меньшим числом атомов углерода $\mathrm{C}_{5} \mathrm{H}_{11} \mathrm{COOH}-\mathrm{C}_{8} \mathrm{H}_{17} \mathrm{COOH}$, что может быть связано с деструкцией углеродной цепи кислот состава $\mathrm{C}_{12} \mathrm{H}_{23} \mathrm{COOH}-\mathrm{C}_{15} \mathrm{H}_{31} \mathrm{COOH}$ (рис. 1).

Одноатомные спирты в кислой фракции представлены гомологическим рядом состава $\mathrm{C}_{14} \mathrm{H}_{29} \mathrm{OH}-$ $\mathrm{C}_{26} \mathrm{H}_{53} \mathrm{OH}$ (рис. 2). Максимум в распределении приходится на соединения с числом атомов углерода 22 и 24. После МА торфа в составе спиртов снижается доля соединений $\mathrm{C}_{18} \mathrm{H}_{37} \mathrm{OH}-\mathrm{C}_{24} \mathrm{H}_{49} \mathrm{OH}$. Незначительное увеличение содержания спиртов с меньшей молекулярной массой может быть связано с их образованием при деструкции длинных углеродных цепей у более высокомолекулярных спиртов.

Таблица 2. Влияние механоактивации торфа на элементный состав липидов

\begin{tabular}{c|c|c|c|c|c|c}
\hline \multirow{2}{*}{$\begin{array}{c}\text { Время м/a, } \\
\text { мин }\end{array}$} & \multicolumn{3}{|c|}{ Содержание, \% мас. } & \multicolumn{2}{c}{ Отношение } \\
\cline { 2 - 7 } & $\mathrm{C}$ & $\mathrm{H}$ & $\mathrm{N}$ & $\mathrm{O}+\mathrm{S}$ & $\mathrm{H} / \mathrm{C}$ & $\mathrm{O} / \mathrm{C}$ \\
\hline 0 & 71,2 & 10,6 & 0,6 & 17,6 & 1,79 & 0,19 \\
2 & 65,0 & 9,1 & 1,0 & 24,9 & 1,68 & 0,29 \\
5 & 59,1 & 10,1 & 0,8 & 30,0 & 2,05 & 0,38 \\
\hline
\end{tabular}

Таблица 3. Влияние механоактивации торфа на кислотное, перекисное и йодное число липидов

\begin{tabular}{c|c|c|c}
\hline $\begin{array}{c}\text { Время м/о, } \\
\text { мин }\end{array}$ & $\begin{array}{c}\text { Кислотное число, } \\
\text { мг КОН/г }\end{array}$ & $\begin{array}{c}\text { Перекисное число, } \\
\text { моль/кг }\end{array}$ & $\begin{array}{c}\text { Йдное число, } \\
\text { г/100 г }\end{array}$ \\
\hline Без обработки & 46,8 & 120 & 12,3 \\
2 & 52,7 & 116 & 16,2 \\
5 & 58,6 & 114 & 11,1 \\
\hline
\end{tabular}

Таблица 4. Состав кислородсодержащих соединений в кислой фракции липидов

\begin{tabular}{l|c|c}
\hline \multirow{2}{*}{ Соединения } & \multicolumn{2}{|c}{ Содержание, \% отн. на кислую фракцию } \\
\cline { 2 - 3 } & до обработки & после МА \\
\hline Кислоты насыщенные & 16,7 & 14,7 \\
Спирты & 34,1 & 27,7 \\
Кетоны & 5,9 & 6,3 \\
Альдегиды & 6,7 & 1,1 \\
Метиловые эфиры & 0,5 & 1,1 \\
Неидентифицированные & 36,1 & 48,2 \\
\hline
\end{tabular}




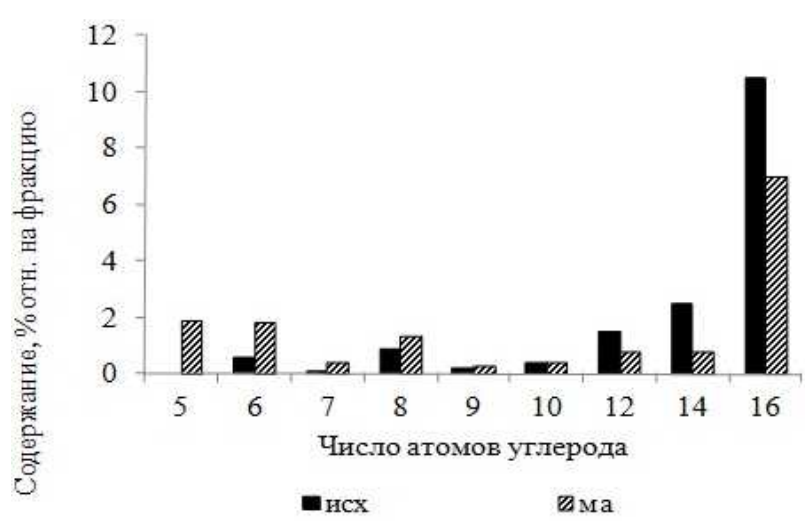

Рис. 1. Молекулярно-массовое распределение насыщенных кислот в кислой фракции липидов из исходного и механоактивированного торфа

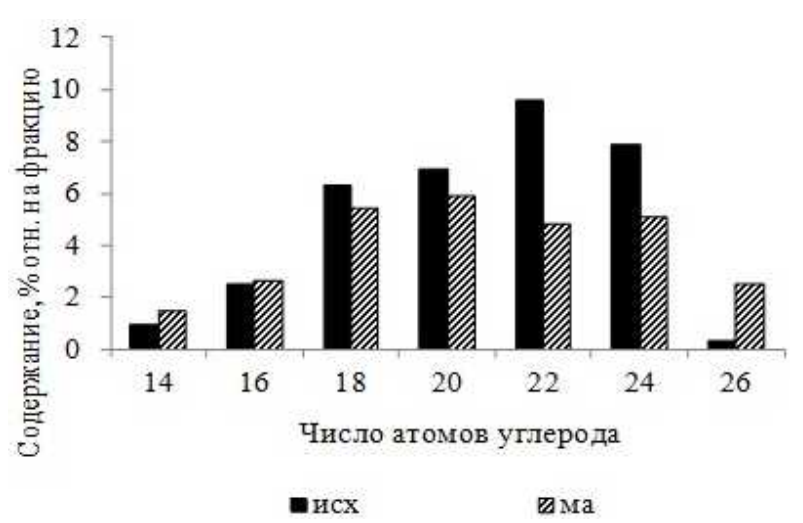

Рис. 2. Молекулярно-массовое распределение спиртов в кислой фракции

В кислой фракции липидов обнаружены кетоны с числом атомов углерода 18 и 19 (рис. 3). После МА суммарное количество кетонов возрастает, а число углеродных атомов в молекулах уменьшается до $11,13,15,17$ с максимумом, приходящимся на соединение состава $\mathrm{C}_{17} \mathrm{H}_{34} \mathrm{O}$. Образование кетонов с меньшей молекулярной массой возможно за счет деструкции алкильных цепей. Кетоны могут окисляться с разрывом углеродной цепи до кислот.

Количество метиловых эфиров, обнаруженных в кислой фракции, незначительно до и после МА торфа (табл. 4). В исходном образце присутствуют эфиры состава $\mathrm{C}_{17} \mathrm{H}_{32} \mathrm{O}_{2}$ и $\mathrm{C}_{23} \mathrm{H}_{44} \mathrm{O}_{2}$. В механоактивированном образце появляются соединения с числом атомов углерода 16, 18, 19 и 23. Максимальным содержанием отличаются эфиры состава $\mathrm{C}_{19} \mathrm{H}_{36} \mathrm{O}_{2}$ и $\mathrm{C}_{23} \mathrm{H}_{44} \mathrm{O}_{2}$.

Альдегиды в исходном образце представлены соединениями 14-октадеценаль, 10-октадеценаль, 2-метил-10-ундецен-1-аль. После МА изменяется не только содержание альдегидов, но и их состав, включающий только 2-метил-10-ундецен-1-аль (табл. 4). Наличие в молекулах связи -C=O обеспечивает высокую реакционную способность альдегидов. Альдегиды легко окисляются в карбоновые кислоты, реакции гидратации переводят их в спирты. В случае МА отмечается в первую очередь деструкция 14-октадеценаль, 10-октадеценаль и снижается содержание 2-метил-10-ундецен-1-аль.

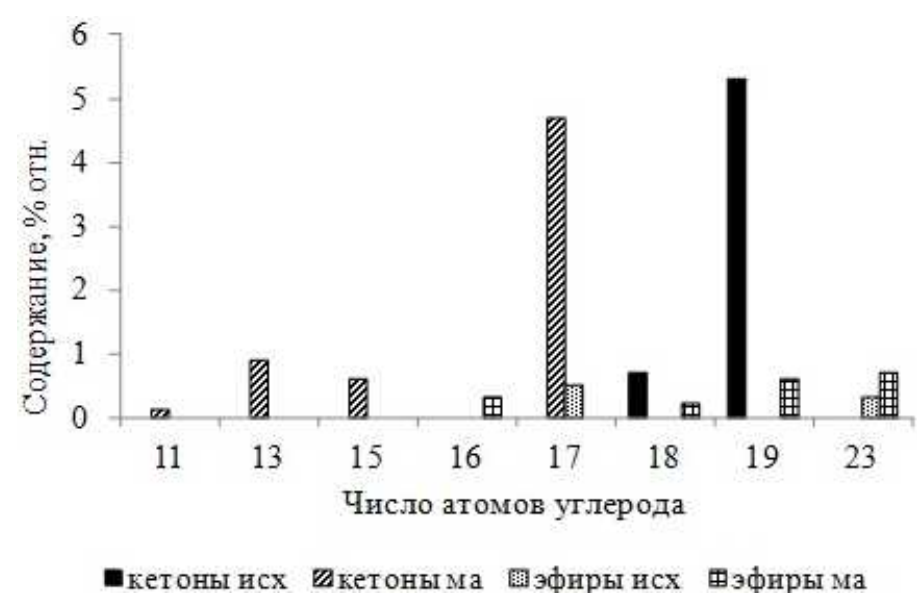

Рис. 3. Молекулярно-массовое распределение кетонов и эфиров в кислой фракции липидов из исходного и механоактивированного торфа

\section{Выводы}

Механоактивация торфа приводит к повышению выхода липидов и содержания в них восков, что определяется разрушением надмолекулярной структуры связанных компонентов в торфе, разрывом гликозидной связи в гликолипидах. Механохимические превращения карбоновых кислот в кислых фракциях липидов сопровождаются незначительным снижением их количества и увеличением доли соединений с меньшей молекулярной массой за счет разрыва углеродной цепи. После МА торфа отмечается существенное уменьшение содержания насыщенных одноатомных спиртов, что, возможно, также происходит при разрыве углеродной цепи и реакциях дегидратации. Изменения в составе и количестве альдегидов связаны с их деструкцией. 


\section{Список литературы}

1. Буркова В.Н., Венгеровский А.И., Опалинская А.М. Антиоксидантные свойства и биологическая активность липидов современных озерных осадков различного генезиса. Препринт. Томск, 1988. 35 с.

2. Юдина Н.В., Буркова В.Н., Ополинская А.М. Антиоксиданты в органическом веществе растений торфообразователей и торфов Западной Сибири // Химия твердого топлива. 1991. №4. С. 42.

3. Буркова В.Н., Писарева С.И., Юдина Н.В. Распределение антиоксидантов в биологических и геоорганических объектах // Геохимия. 1998. №11. С. 1164.

4. Белькевич П.И., Голованов Н.Г., Долидович Е.Ф. Битумы торфа и бурого угля. Минск, 1989. 127 с.

5. Овчинников Ю.А. Биоорганическая химия. М., 1987. 515 с.

6. Жеребцов С.И., Моисеев А.И. Состав восковой фракции битумоидов метилированных бурых углей // Химия твердого топлива. 2009. №2. С. 12-21.

7. Жеребцов С.И., Мусин Ю.В., Моисеев А.И. Влияние алкилирования на состав и выход битумоидов торфа // Химия растительного сырья. 2009. №2. С. 125-130.

8. Chuev V.P., Kameneva O.D., Chikalo T.M. Use of mechanochemical activation to modify properties of bioactive compounds // Сибирский химический журнал. 1991. Вып. 5. С. 156-157.

9. Vedernikov N., Karlivans V., Roze I., Rolle A. Mechanochemical destruction of plant raw materials - polysaccharides in presence of small amounts of concentrated sulfuric acid // Сибирский химический журнал. 1991. Вып. 5. С. $67-72$.

10. Ломовский О.И., Болдырев В.В. Механохимия в решении экологических задач. Новосибирск, 2006. 221 с.

11. Гирина Л.В., Лукьяненко Л.В., Аммосова Я.М. и др. Изменение физико-химических свойств бурого угля при механических воздействиях различного характера // Химия твердого топлива. 1991. №5. С. 37-42.

12. Пройдаков А.Г., Полубенцев А.В., Бачин Д.Е. Механохимические превращения угольных асфальтенов // Химия твердого топлива. 1994. №4. С. 40-44.

13. Гаврильчик А.П., Кашинская Т.Я., Пискунова Т.А. Изменение выхода и химического состава битумов при механоактивации торфа // Природопользование. 2001. Вып. 7. С. 161-163.

14. Гонцов А.А., Гонцова С.А., Пахомова О.В. Механохимические превращения высших жирных кислот твердых горючих ископаемых // Химия твердого топлива. 1992. №4. С. 11-17.

15. Кейтс М. Техника липидологии. М., 1985. 333 с.

16. Бутылкина А.И., Левданский В.А., Калачева Г.С., Кузнецов Б.Н. Хромато-масс-спектрометрическое изучение химического состава гексанового экстракта коры кедра // Journal of Siberian Federal University. Chemistry. 2008. Т. 3, №1. С. 293-300.

17. Хмельницкий Р.А., Бродский Е.С. Хромато-масс-спектрометрия. М., 1984. 216 с.

18. Лиштван И.И., Базин Е.Т., Косов В.И. Физические свойства торфа и торфяных залежей. Минск, 1985. 240 с.

19. Иванов А.А., Савельева А.В., Юдина Н.В., Ломовский О.И. Изменение состава и свойств липидов торфов при механохимической обработке // Журнал прикладной химии. 2005. Т. 78, вып. 3. С. 512-516.

Поступило в редакциию 11 декабря 2012 2. 
Savelyeva A.V., Yudina N.V.* MECHANOCHEMICAL TRANSFORMATIONS OF OXYGEN-CONTAINING LIPIDE COMPOUNDS OF PEAT

Institute of Petroleum Chemistry SB RAS, Academichesky Ave. 4, Tomsk, 634021 (Russia), e-mail: natal@ipc.tsc.ru

The effect of mechanical activation of peat on the changes in lipid yield and in composition of resin fraction is shown. Mechanochemical transformations of carboxylic acids in acidic lipid fractions are followed by a slight decrease in their number and increase in the fraction of compounds with lower molecular weight. A significant decrease in saturated monohydric alcohols is observed after the mechanical activation of peat.

Keywords: mechanical activation, peat lipids, fatty acids, alcohols, ketones.

\section{References}

1. Burkova V.N., Vengerovskii A.I., Opalinskaia A.M. Antioksidantnye svoistva i biologicheskaia aktivnost' lipidov sovremennykh ozernykh osadkov razlichnogo genezisa. Preprint. [Antioxidant properties and biological activity of lipid modern lacustrine sediments of different genesis. Preprint.]. Tomsk, 1988, 35 p. (in Russ.).

2. Iudina N.V., Burkova V.N., Opolinskaia A.M. Khimiia tverdogo topliva, 1991, no. 4, p. 42. (in Russ.).

3. Burkova V.N., Pisareva S.I., Iudina N.V. Geokhimiia, 1998, no. 11, p. 1164. (in Russ.).

4. Bel'kevich P.I., Golovanov N.G., Dolidovich E.F. Bitumy torfa i burogo uglia. [Bitumen peat and brown coal]. Minsk, 1989, 127 p. (in Russ.).

5. Ovchinnikov Iu.A. Bioorganicheskaia khimiia. [Bioorganic chemistry]. Moscow, 1987, 515 p. (in Russ.).

6. Zherebtsov S.I., Moiseev A.I. Khimiia tverdogo topliva, 2009, no. 2, pp. 12-21. (in Russ.).

7. Zherebtsov S.I., Musin Iu.V., Moiseev A.I. Khimiia rastitel'nogo syr'ia, 2009, no. 2, pp. 125-130. (in Russ.).

8. Chuev V.P., Kameneva O.D., Chikalo T.M. Siberian Chemical Journal, 1991, no. 5, pp. 156-157.

9. Vedernikov N., Karlivans V., Roze I., Rolle A. Siberian Chemical Journal, 1991, no. 5, pp. 67-72.

10. Lomovskii O.I., Boldyrev V.V. Mekhanokhimiia v reshenii ekologicheskikh zadach. [Mechanochemistry in solving environmental problems]. Novosibirsk, 2006, 221 p. (in Russ.).

11. Girina L.V., Luk'ianenko L.V., Ammosova Ia.M. Khimiia tverdogo topliva, 1991, no. 5, pp. 37-42. (in Russ.).

12. Proidakov A.G., Polubentsev A.V., Bachin D.E. Khimiia tverdogo topliva, 1994, no. 4, pp. 40-44. (in Russ.).

13. Gavril'chik A.P., Kashinskaia T.Ia., Piskunova T.A. Prirodopol'zovanie, 2001, no. 7, pp. 161-163. (in Russ.).

14. Gontsov A.A., Gontsova S.A., Pakhomova O.V. Khimiia tverdogo topliva, 1992, no. 4, pp. 11-17. (in Russ.).

15. Keits M. Tekhnika lipidologii. [Technique lipidology]. Moscow, 1985, 333 p. (in Russ.).

16. Butylkina A.I.,. Levdanskii V.A, Kalacheva G.S., Kuznetsov B.N. Journal of Siberian Federal University. Chemistry, 2008, vol. 3, no. 1, pp. 293-300. (in Russ.).

17. Khmel'nitskii R.A., Brodskii E.S. Khromato-mass-spektrometriia. [Chromatography-mass spectrometry]. Moscow, 1984, 216 p. (in Russ.).

18. Lishtvan I.I., Bazin E.T., Kosov V.I. Fizicheskie svoistva torfa i torfianykh zalezhei. [Physical properties of peat and peat deposits]. Minsk, 1985, 240 p. (in Russ.).

19. Ivanov A.A., Savel'eva A.V., Iudina N.V., Lomovskii O.I. Zhurnal prikladnoi khimii, 2005, vol. 78, no. 3, pp. $512-516$. (in Russ.).

\footnotetext{
* Corresponding author.
} 